\title{
Comparison of universal screening with targeted high-risk case finding for diagnosis of thyroid disorders
}

\author{
Sima Nazarpour, Fahimeh Ramezani Tehrani ${ }^{1}$, Masoumeh Simbar, Maryam Tohidi ${ }^{2}$, \\ Hamid AlaviMajd ${ }^{3}$ and Fereidoun Azizi ${ }^{4}$ \\ Department of Reproductive Health and Midwifery, Faculty of Nursing and Midwifery, Shahid Beheshti University of \\ Medical Sciences and Health Services, Tehran, Iran, ${ }^{1}$ Reproductive Endocrinology Research Center, Research Institute \\ for Endocrine Sciences, Shahid Beheshti University of Medical Sciences, Tehran, Iran, ${ }^{2}$ Prevention of Metabolic \\ Disorders Research Center, Research Institute for Endocrine Sciences, Shahid Beheshti University of Medical Sciences, \\ Tehran, Iran, ${ }^{3}$ Department of Biostatistics, Faculty of Paramedicine, Shahid Beheshti University of Medical Sciences \\ and Health Services, Tehran, Iran and ${ }^{4}$ Endocrine Research Center, Research Institute for Endocrine Sciences, \\ Shahid Beheshti University of Medical Sciences, Tehran, Iran
}

Correspondence should be addressed to F Ramezani Tehrani Email

fah.tehrani@gmail.com

\begin{abstract}
Objective: Debate about the need for universal screening of thyroid dysfunction in pregnancy is ongoing. The present study aimed to compare universal screening with targeted high-risk case findings for early diagnosis of thyroid disorders in Iranian pregnant women.

Study design: This cross-sectional prospective study was carried out on 1600 pregnant women in their first trimester. A checklist, including all related risk factors recommended by The American Thyroid Association, was completed for all participants. Serum concentrations of thyroxine $\left(T_{4}\right), T$-uptake, TSH and thyroid peroxidase antibody (TPOAb) were measured and thyroid status was documented, based on hormonal measurements and clinical examinations.

Results: There were 656 women (44.3\%) that had at least one risk factor for thyroid diseases and were eligible for the targeted high-risk case finding (high-risk group) approach, while $55.7 \%$ had no risk factors (low-risk group). Using the universal screening approach, there were 974 women (65.8\%) with normal thyroid status and 506 participants (34.2\%) with thyroid disturbances, including overt hyperthyroidism $(0.7 \%)$, overt hypothyroidism (1.1\%), subclinical hypothyroidism (30.1\%; positive TPOAb $(5.5 \%)$ and negative TPOAb (24.6\%); and euthyroid and positive TPOAb $(2.3 \%)$. Of women with thyroid dysfunction, $64.4 \%$ were in the high-risk group and $35.6 \%$ were in the low-risk group $(P<0.0001)$. Conclusions: The targeted high-risk case finding approach overlooks about one-third of pregnant women with thyroid dysfunction. If ongoing prospective trials provide evidence on the efficacy of treating subclinical hypothyroidism in pregnancy, in populations with a low prevalence of presumed risk factors, the targeted high-risk case finding approach will be proven inefficient.
\end{abstract}

\section{Introduction}

Thyroid dysfunction is the second most common endocrine disturbance in women of reproductive age $(1,2)$, with a high prevalence in pregnant women. About 2-3\% of pregnant women are diagnosed with hypothyroidism (0.3-0.5\% with overt hypothyroidism and $2-2.5 \%$ with (c) 2016 European Society of Endocrinology Printed in Great Britain subclinical hypothyroidism), whereas hyperthyroidism has been reported in $0.1-0.4 \%$ of pregnant women. Furthermore, about $10-20 \%$ of all euthyroid pregnant women are positive for thyroid antibodies (3). While complications of hypothyroidism or overt 
hyperthyroidism in pregnancy outcomes as well as neonatal and childhood development are well known (4, 5, $6,7,8)$, there is still no consensus on the association of subclinical thyroid disorders or increasing thyroid antibodies with complications of pregnancy and childhood. Some studies have shown that subclinical hypothyroidism and thyroid autoimmunity are associated with adverse maternal and fetal outcomes $(8,9,10,11,12,13)$.

The possible adverse outcomes of thyroid disorders in pregnancy are causing an increase in the tendency for universal screening $(14,15)$. However, the American Association of Clinical Endocrinologists (AACE), American Thyroid Association (ATA) and American College of Obstetrics and Gynecology (ACOG) do not recommend universal thyroid assessment for every pregnant woman, and suggest the targeted high-risk case finding approach $(4,16,17)$, an approach which needs to be evaluated for its effectiveness in routine clinical practice (18).

Several studies comparing various screening approaches, reported that not using the universal approach resulted in overlooking a significant number of pregnant women with thyroid dysfunction $(19,20)$. It has been shown that 30-90\% of women with thyroid disturbances may be omitted using the targeted high-risk case finding approach $(20,21,22,23,24,25)$. With current increases in potential risk factors, the efficiency of the screening method has also increased. As Potlukova et al. (26) reported, by including age $\geq 30$ years as a risk factor, the sensitivity of high-risk case finding strategy increased from $55.3-85.6 \%$.

Given the differences in prevalence of potential risk factors in various societies, it is reasonable to identify the majority of pregnant women with thyroid dysfunction overlooked by using the targeted high-risk case finding approach in certain races and societies with different risk factors and iodine status. In this study, we aimed to compare the universal screening with targeted high-risk case finding approaches for early diagnosis of thyroid disorders in pregnant Iranian women.

\section{Subjects and methods}

This is a prospective study carried out in Tehran from September 2013 to September 2014. In this study, 1600 pregnant women in their first trimester were selected, using a cluster sampling method from among those receiving prenatal care in centers under coverage of Shahid Beheshti University of Medical Sciences, which provides health services to over two-thirds of Tehran's population. A written informed consent form was obtained from all participants and the study was approved by the Ethical committee of the Research Institute of Endocrine Sciences. A comprehensive questionnaire including demographic, reproductive, medical and prenatal history was filled out during face-to-face interviews. A checklist including all potential risk factors, as recommended by the American Thyroid Association (27), was completed for all participants and physical exams including thyroid, weight, height, systolic and diastolic pressure. Overnight blood samples were collected, following centrifugation they were sent to the Research Institute of Endocrine Sciences of Shahid Beheshti University of Medical Sciences for thyroid hormonal assessment including thyroxin $\left(\mathrm{T}_{4}\right)$, T-uptake, thyrotropin (TSH) and thyroid peroxidase antibody (TPOAb). Since free $\mathrm{T}_{4}\left(\mathrm{FT}_{4}\right)$ immunoassays may be influenced by pregnancy-related changes of serum thyroxin binding globulin and albumin, in a method-specific manner, $\mathrm{FT}_{4}$ index $\left(\mathrm{FT}_{4} \mathrm{I}\right)$ was used to assess $\mathrm{FT}_{4}$ status (28).

Pregnant women, aged $<18$ years $(n=52)$, those with twin pregnancies $(n=24)$ and those diagnosed with thyroid diseases $(n=44)$ were excluded from this study. Gestational age was calculated according to the first day of their last menstrual cycle (LMP) (for women with regular cycles), and/or ultrasonography for those with irregular cycles or those who could not remember their LMP.

Using RIA and immunoradiometric assay (IRMA), $\mathrm{T}_{4}$ and TSH were measured by commercial kits (Izotop Kit, Budapest co., Hungary) and the Gama-counter (Dream Gamma-10, Goyang-si, Gyeonggi-do, South Korea). T-uptake and TPOAb were measured by the enzyme immunoassay (EIA) (Diaplus Kit, San Francisco, CA, USA) and immunoenzymometric assay (IEMA) (Monobind Kit, Costa Mesa, CA, USA), using a calibrated ELISA reader (Sunrise, Tecan Co., Salzburg, Austria). Inter and intra assay coefficients of variation for $\mathrm{T}_{4}, \mathrm{~T}$-uptake, TSH and TPO-Ab were 1.1 and 3.9\%, 2.2 and 4.3\%, 1.9 and 4.7\%, and 1.0 and $1.6 \%$ respectively.

Participants were categorized into two groups, according to their risk factors, as the low-risk (without any risk factors) and the high-risk (with one or more risk factors) groups.

Based on results of laboratory examinations, patients with TSH level $<2.5 \mu \mathrm{IU} / \mathrm{ml}$, FTI: $1-4.5$ and TPO antibodies $<50 \mathrm{IU} / \mathrm{ml}$ (negative), were considered normal. Patients with TSH levels $>10 \mu \mathrm{IU} / \mathrm{ml}$, or $5-10 \mu \mathrm{IU} / \mathrm{ml}$ and FTI $<1$, were diagnosed as overt hypothyroidism and those with TSH levels $<0.02 \mu \mathrm{IU} / \mathrm{ml}$ and FTI $>4.5$ as overt hyperthyroidism. Those with TSH levels between 2.5 and $10 \mu \mathrm{IU} / \mathrm{ml}$, and FTI between 1 and 
4.5, as sub-clinically hypothyroid, regardless of TPOAb status, whether positive or negative. Women with TSH levels $<2.5 \mu \mathrm{IU} / \mathrm{ml}$, FTI $<1$ and TPO antibodies $<50 \mathrm{IU} / \mathrm{ml}$ (negative), were considered as isolated hypothyroxinemia and those with TSH levels $<2.5 \mu \mathrm{IU} / \mathrm{ml}$, FTI between 1 and 4.5 and TPO antibodies $>50 \mathrm{IU} / \mathrm{ml}$ (positive), were considered as positive TPOAb euthyroid.

\section{Statistical analysis}

Continuous variables were checked for normality using the one-sample Kolmogorov-Smirnoff test. Categorical variables are expressed as percentages and were compared using Pearson's $\chi^{2}$ test. Distributions of variables between the two groups were compared using $t$ test and expressed as mean \pm s.D. Logistic regression was used to identify the association between each risk factor and thyroid dysfunction. Statistical analysis was performed by using SPSS software version 18 .

\section{Results}

Demographic and reproductive characteristics of study participants are presented in Table 1. Mean \pm s.D.s of age, BMI and gestational age of the women were $27.4 \pm 4.9$ years, $25.2 \pm 4.7 \mathrm{~kg} / \mathrm{m}^{2}$ and $11.4 \pm 4.2$ weeks respectively. Past history of thyroid disorders was given by 57 (3.9\%) women (31 women with hypothyroidism, 18 with hyperthyroidism), but 8 women were unaware of the type of their disorder). Family history of thyroid disorders was reported by 168 (11.4\%) women.

Table 1 Characteristics of study population $(n=1480)$.

\begin{tabular}{|c|c|}
\hline Characteristics & \\
\hline Maternal age (year)* & $27.4( \pm 4.9)$ \\
\hline Maternal BMI $\left(\mathrm{kg} / \mathrm{m}^{2}\right)$ & $25.2( \pm 4.7)$ \\
\hline Gestational age (weeks)* & $11.4( \pm 4.2)$ \\
\hline \multicolumn{2}{|l|}{ Gestational age, $n(\%)$} \\
\hline$<14$ weeks & $1108(74.9)$ \\
\hline 14-20 weeks & $372(25.1)$ \\
\hline History of infertility $n(\%)$ & $66(4.5)$ \\
\hline $\begin{array}{l}\text { Current pregnancy using infertility } \\
\text { medication, } n(\%)\end{array}$ & $12(0.8)$ \\
\hline \multicolumn{2}{|l|}{ Reproductive history } \\
\hline Primigravida & $504(34.1)$ \\
\hline Multigravida & $976(56.9)$ \\
\hline Abortion, $n(\%)$ & $244(16.5)$ \\
\hline Stillbirth, $n(\%)$ & $6(0.4)$ \\
\hline Previous history of thyroid disease, $n(\%)$ & $57(3.9)$ \\
\hline Family history of thyroid disease, $n(\%)$ & $168(11.4)$ \\
\hline
\end{tabular}

Using the predefined classification, $65.8 \%(n=974)$ had normal thyroid function and $34.2 \%(n=506)$ had thyroid disorders, including overt hyperthyroidism $(0.7 \%$, $n=10)$, overt hypothyroidism $(1.1 \%, n=17)$, subclinical hypothyroidism $(30.1 \%, n=445)$, including positive TPOAb (5.5\%) and TPOAb negative (24.6\%). Overall, $31.2 \%(n=462)$ had hypothyroidism $(1.1 \%$ with overt hypothyroidism and $30.1 \%$ subclinical). Finally, $8.9 \%$ $(n=132)$ had positive TPOAb, $2.3 \%(n=34)$ being euthyroid, with positive TPOAb.

Table 2 presents the prevalence of each risk factor in women with and without thyroid dysfunction. The three most prevalent risk factors were age $\geq 30$ years (30.7\%), history of abortion (16.5\%) and family history of thyroid disorders (11.4\%).

In the low-risk group, mean BMI and gestational age of those women with thyroid disorders were significantly higher than those without disorders. In the high-risk group, mean age of women without thyroid disorders was significantly higher than those with the disorders. Thyroid disorders were identified in 39.6 and $27.4 \%$ of women in the high- and low-risk groups respectively $(P<0.0001)$. Prevalence of abnormal thyroid tests was 64.4 and $35.6 \%$ in the high- and low-risk groups respectively.

Eight cases with hyperthyroidism were in the highrisk group and two were in the low-risk group; $88.2 \%$ $(n=15)$ of cases with overt hypothyroidism were in the high-risk group and $11.8 \%(n=2)$ were in the low-risk one. Of cases with subclinical hypothyroidism, $60.9 \%(n=271)$ were in the high-risk group and $39.1 \%(n=174)$ were in the low-risk group.

Logistic regression analysis demonstrated 15 risk factors, previous history (Odds: 4.44, 95\% CI: 2.51-7.84, $P<0.001)$ or family history of thyroid disorders (Odds: 1.44, 95\% CI: $1.04-1.99, P=0.031)$ was associated with thyroid dysfunction (Table 3).

\section{Discussion}

Using the targeted high-risk case finding approach for thyroid dysfunction overlooks about one out of every three pregnant women suffering from these disorders. Of all the risk factors considered for this approach, only past history (Odds: 4.44, 95\% CI: 2.51-7.84) or family history of thyroid disorders (Odds: $1.44,95 \%$ CI: 1.04-1.99) were associated with thyroid dysfunction.

Debate about the need for universal screening of thyroid dysfunction in pregnancy is ongoing. Despite lack of sufficient evidence that identification and treatment of pregnant women with subclinical hypothyroidism 
Table 2 The prevalence of risk factors in women with and without thyroid dysfunction. Data are presented as $n(\%)$.

Risk factor

Women with previous history of thyroid dysfunction Women currently receiving L-thyroxine replacement

Women treated with radioactive iodine

Women with prior therapeutic head or neck irradiation or prior thyroid surgery**

Women with a family history or autoimmune thyroid disease or hypothyroidism

Women with goiter

Women with thyroid antibodies, primarily thyroid peroxidase antibodies

Women with type $1 \mathrm{DM}$ or other autoimmune disorders**

Women with a prior history of miscarriage or preterm delivery

Women with a prior history of preterm delivery

Women with infertility

Women with morbid obesity (BMI $\geq 40)$

Women aged $\geq 30$ years

\begin{tabular}{c}
$\begin{array}{c}\text { With thyroid } \\
\text { dysfunction }\end{array}$ \\
\hline $39(7.7)$ \\
$5(1.0)$ \\
0 \\
$2(0.4)$
\end{tabular}

$70(13.8)$

$6(1.2)$

$134(26.5)$

\section{0}

$80(15.8)$

$8(3.0)$

$22(4.3)$

$2(0.4)$

$150(29.6)$

\begin{tabular}{ccrr}
$\begin{array}{c}\text { Without thyroid } \\
\text { dysfunction }\end{array}$ & & \multicolumn{1}{c}{ Total } \\
\cline { 1 - 1 } $18(1.8)$ & & $57(3.9)$ \\
$2(0.2)$ & & $7(0.5)$ \\
$2(0.2)$ & & $2(0.1)$ \\
0 & & $2(0.1)$
\end{tabular}

$98(10.1)$

$168(11.4)$

$18(1.8)$

0

$24(1.6)$

$132(8.9)$

$4(0.3)$

$244(16.5)$

$26(1.8)$

$66(4.5)$

$8(0.5)$

$454(30.7)$

**There was no pregnant woman with previous history of other autoimmune disorders or history of head/neck irradiation.

improves maternal or neonatal outcomes, the low cost treatment and widespread availability of screening test is causing the universal screening approach to have fastgaining popularity $(29,30)$.

In this study, we found that when potential risk factors for thyroid disease are used, case finding misses $20.0 \%$ of those with hyperthyroidism, $11.8 \%$ of those with overt hypothyroidism or $39.1 \%$ of those with subclinical hypothyroidism. In agreement with our results, Vaidya et al. (20) reported that about 30\% of women with hypothyroidism and 69\% of women with hyperthyroidism were overlooked using the targeted high-risk case finding approach. Wang et al. (24) reported that a case identification screening strategy failed to diagnose $81.6 \%$ of pregnant women with hypothyroidism and $80.4 \%$ of pregnant women with hyperthyroidism. In a retrospective cohort study, Chang et al. (22) also reported that $80 \%$ of women with high TSH levels could not be diagnosed using the high-risk case finding approach. The Yang et al. (25) study showed that using the high-risk case finding strategy, all the women with overt hypothyroidism and $66.7 \%$ of women with overt hyperthyroidism were identified in the first trimester, indicating that this method is inefficient for identification of patients with overt thyroid disorders. The Ohashi et al. (23) study also showed that targeted high-risk case finding for diagnosis of thyroid disorders in pregnant women identified only $10 \%$ of women with thyroid dysfunction, i.e. $90 \%$ of

Table 3 The odds ratio and $95 \% \mathrm{Cl}$ of various risk factors for prediction of thyroid disturbances.

\begin{tabular}{l} 
Risk factors \\
\hline Previous history of a thyroid disorder \\
Family history of a thyroid disorder \\
History of thyroid drug use \\
History of radioactive iodine therapy \\
Goiter \\
History of type 1 diabetes mellitus \\
History of miscarriage \\
History of preterm delivery \\
History of other autoimmune disorders \\
Infertility \\
History of head/neck irradiation \\
Morbid obesity (BMI $\geq 40$ ) \\
Women aged $\geq 30$
\end{tabular}

\begin{tabular}{c}
\hline $\operatorname{Exp}(\mathbf{B})$ \\
\hline 4.44 \\
1.44 \\
4.85 \\
0.00 \\
0.64 \\
0.00 \\
0.93 \\
0.92 \\
- \\
0.96 \\
- \\
0.64 \\
0.93 \\
\hline
\end{tabular}

\begin{tabular}{c}
\hline $95 \% \mathrm{Cl} \operatorname{Exp}$ (B) \\
\hline $2.51-7.84$ \\
$1.03-1.99$ \\
$0.94-25.09$ \\
0.00 \\
$0.25-1.62$ \\
0.00 \\
$0.69-1.24$ \\
$0.40-2.14$ \\
- \\
$0.57-1.62$ \\
- \\
$0.13-3.18$ \\
$0.74-1.17$
\end{tabular}

\begin{tabular}{c}
\hline $\boldsymbol{P}$ \\
\hline$<0.001$ \\
0.031 \\
0.060 \\
0.999 \\
0.343 \\
0.999 \\
0.613 \\
0.847 \\
- \\
0.881 \\
- \\
0.585 \\
0.535 \\
\hline
\end{tabular}

www.eje-online.org 
women with thyroid dysfunction were not identified. Ahmed et al. (21) also reported that considering the case finding approach introduced by The Endocrine Association, $34.5 \%$ of pregnant women with clinical or subclinical hypothyroidism were overlooked. These variations in results could be partly explained by using various thresholds for TSH, FTI and TPOAb, while we defined normal thyroid status as TSH $<2.5 \mu \mathrm{IU} / \mathrm{ml}$, FTI: $1-4.5$ and TPO antibodies $<50 \mathrm{IU} / \mathrm{ml}$. Yang et al. (25) used cut-off values of $3.47 \mathrm{mU} / \mathrm{l}$ in the first trimester and $3.81 \mathrm{mU} / 1$ in the second trimester for TSH. Various prevalence of assumed risk factors for thyroid disorders (e.g. age and BMI) in different populations could partly explaine these variations in results. In the current study, the average age was $27.4 \pm 4.9$ years, which differed to that (30.8 \pm 4.7 years) of the Ohashi et al. study (23). In addition, these variations may be due to the differences in the iodine sufficiency status of regions, because in areas with severe iodine deficiency resulting in a higher prevalence of goiter, more women have the risk factor required for being eligible for the case targeted high-risk case finding approach.

There is no consensus on the risk factors that need to be included in a case finding approach. While American Thyroid Association and European societies guidelines considered age $\geq 30$ years as a risk factor and suggested screening all women over the age of 30 years, there is insufficient evidence on the association between age and abnormal thyroid function (31). It has been shown that the addition of women age $\geq 30$ years increased the proportion of women identified in a case finding approach from 55.3 to $85.6 \%$ (26). It seems that due to wide differences in the prevalence of these risk factors in various communities $(32,33)$, thyroid screening policies need to be evidence-based for each society (27).

The current study showed that considering the relatively low prevalence of risk factors among Iranian pregnant women, over one-third of women with thyroid disorders $(35.6 \%)$ are missed by not using universal screening. However, those overlooked women mostly had subclinical thyroid disorders $(34.4 \%, n=174)$ but current data on the impact of treating these women are limited and conflicting. While some studies demonstrate subclinical hypothyroidism results in adverse outcomes of pregnancy $(3,13,34,35,36,37,38)$ and intervention with $\mathrm{L}$-thyroxine $\left(\mathrm{L}-\mathrm{T}_{4}\right)$ may prevent these complications $(39,40)$. However, this has not been reported by others $(41,42)$.

The present study showed that among the risk factors for thyroid dysfunction, past and family histories of thyroid disorders are significant prognostic factors for prediction of thyroid dysfunction. Pregnant women with a history of thyroid disorders had 4.5 (95\% CI) times more chance of having thyroid dysfunction, than those without this history, and a person with a family history of thyroid disorders has a 1.5 times higher chance of having thyroid dysfunction (95\% CI) compared to women without this history. In agreement with our results, Dehghani Zahedani et al. (2011) and Feki et al. (2008) reported predictive ability of past history of thyroid diseases for thyroid disorders in pregnant women, but they demonstrated no significant relationship between a positive family history of thyroid dysfunction and thyroid disorders in pregnancy $(41,42)$, which was reported by Vaidya et al. (20) and Bulmus et al. (43). Data also shows that comprehensive assessment of medical and family history of pregnant women could identify $6.7 \%$ of thyroid diseases among the pregnant women (43).

The main strength of this study is its methodology, because it is a study conducted mainly on pregnant Iranian women in their first trimester. Comprehensive thyroid assessment including history, physical exam and thyroid function tests were done for all study participants, while in some other studies these have not been measured for all participants $(20,23,44)$. However, the results of our study cannot be generalized to other areas with different statuses of iodine sufficiency or other underlying risk factors.

In conclusion, targeted high-risk case finding approach overlooks about one-third of Iranian pregnant women suffering from some type of thyroid dysfunction. While universal screening for thyroid diseases in pregnancy seems to be reasonable considering the low cost treatment and widespread availability of screening test, as current data on the impact of treating subclinical hypothyroidism are limited and conflicting, it cannot yet be recommended. If ongoing prospective trials provide evidence on the efficacy of treating subclinical hypothyroidism in pregnancy, the targeted high-risk case finding approach will be proven inefficient, especially in populations with a low prevalence of presumed risk factors.

Declaration of interest

The authors declare that there is no conflict of interest that could be perceived as prejudicing the impartiality of the research reported.

\section{Funding}

This research did not receive any specific grant from any funding agency in the public, commercial or not-for-profit sector. 


\section{Acknowledgements}

We are indebted to each of the study participants for the substantial time and effort contributed to this study. Acknowledgments are also due to the staff of the prenatal care center, under coverage of Shahid Beheshti University of Medical Sciences. My special thanks to Mrs N Shiva for editing the manuscript and personnel of the Research Endocrine Laboratory. This article has been extracted from a PhD thesis and has been done with the financial support of Reproductive Endocrinology Research Center, Research Institute for Endocrine Sciences, Shahid Beheshti University of Medical Sciences.

\section{References}

1 Carney LA, Quinlan JD \& West JM. Thyroid disease in pregnancy. American Family Physician 201489 273-278.

2 Vandana, Kumar A, Khatuja R \& Mehta S. Thyroid dysfunction during pregnancy and in postpartum period: treatment and latest recommendations. Archives of Gynecology and Obstetrics 2014289 1137-1144. (doi:10.1007/s00404-014-3159-y)

3 Negro R \& Mestman JH. Thyroid disease in pregnancy. Best Practice \& Research. Clinical Endocrinology \& Metabolism 201125 927-943. (doi:10.1016/j.beem.2011.07.010)

4 Abalovich M, Amino N, Barbour LA, Cobin RH, De Groot LJ, Glinoer D, Mandel SJ \& Stagnaro-Green A. Management of thyroid dysfunction during pregnancy and postpartum: an Endocrine Society Clinical Practice Guideline. Journal of Clinical Endocrinology and Metabolism 2007 92 (Suppl 8) S1-S47. (doi:10.1210/jc.2007-0141)

5 Casey BM \& Leveno KJ. Thyroid disease in pregnancy. Obstetrics and Gynecology 2006108 1283-1292. (doi:10.1097/01.AOG.0000244103. 91597.c5)

6 Gaberscek S \& Zaletel K. Thyroid physiology and autoimmunity in pregnancy and after delivery. Expert Review of Clinical Immunology 2011 7 697-706; quiz 7. (doi:10.1586/eci.11.42)

7 Julvez J, Alvarez-Pedrerol M, Rebagliato M, Murcia M, Forns J, Garcia-Esteban R, Lertxundi N, Espada M, Tardón A, Riaño Galán I et al. Thyroxine levels during pregnancy in healthy women and early child neurodevelopment. Epidemiology (Cambridge, Mass.) 201324 150-157. (doi:10.1097/EDE.0b013e318276ccd3)

8 Negro R, Formoso G, Mangieri T, Pezzarossa A, Dazzi D \& Hassan H. Levothyroxine treatment in euthyroid pregnant women with autoimmune thyroid disease: effects on obstetrical complications. Journal of Clinical Endocrinology and Metabolism 200691 2587-2591. (doi:10.1210/jc.2005-1603)

9 Casey BM, Dashe JS, Wells CE, McIntire DD, Byrd W, Leveno KJ \& Cunningham FG. Subclinical hypothyroidism and pregnancy outcomes. Obstetrics and Gynecology 2005105 239-245. (doi:10.1097/ 01.AOG.0000152345.99421.22)

10 Chen L \& Hu R. Thyroid autoimmunity and miscarriage: a metaanalysis. Clinical Endocrinology 201174 513-519. (doi:10.1111/ j.1365-2265.2010.03974.x)

11 Stagnaro-Green A \& Glinoer D. Thyroid autoimmunity and the risk of miscarriage. Best Practice \& Research. Clinical Endocrinology \& Metabolism 200418 167-181. (doi:10.1016/j.beem.2004.03.007)

12 Thangaratinam S, Tan A, Knox E, Kilby MD, Franklyn J \& Coomarasamy A. Association between thyroid autoantibodies and miscarriage and preterm birth: meta-analysis of evidence. BMJ 2011 342 d2616. (doi:10.1136/bmj.d2616)

13 Stagnaro-Green A, Chen X, Bogden JD, Davies TF \& Scholl TO. The thyroid and pregnancy: a novel risk factor for very preterm delivery. Thyroid 200515 351-357. (doi:10.1089/thy.2005.15.351)

14 Haddow JE, McClain MR, Palomaki GE, Kloza EM \& Williams J. Screening for thyroid disorders during pregnancy: results of a survey in
Maine. American Journal of Obstetrics and Gynecology 2006194 471-474. (doi:10.1016/j.ajog.2005.07.055)

15 Vila L, Velasco I, Gonzalez S, Morales F, Sanchez E, Torrejon S, Soldevila B, Stagnaro-Green A \& Puig-Domingo M. Controversies in endocrinology: On the need for universal thyroid screening in pregnant women. European Journal of Endocrinology/European Federation of Endocrine Societies 2013170 R17-R30. (doi:10.1530/EJE-13-0561)

16 Committee on Patient Safety and Quality Improvement and Committee on Professional Liability. ACOG Committee Opinion No. 381: subclinical hypothyroidism in pregnancy. Obstetrics and Gynecology 2007110 959-960. (doi:10.1097/01.AOG.0000263932.05511.d4)

17 Surks MI, Ortiz E, Daniels GH, Sawin CT, Col NF, Cobin RH, Franklyn JA, Hershman JM, Burman KD, Denke MA et al. Subclinical thyroid disease: scientific review and guidelines for diagnosis and management. Journal of the American Medical Association 2004291 228-238. (doi:10.1001/jama.291.2.228)

18 Azizi F, Amouzegar A, Mehran L, Alamdari S, Subekti I, Vaidya B, Poppe K, San Luis T Jr \& Akamizu T. Screening and management of hypothyroidism in pregnancy: results of an Asian survey. Endocrine Journal 201461 697-704. (doi:10.1507/endocrj.EJ14-0083)

19 Horacek J, Spitalnikova S, Dlabalova B, Malirova E, Vizda J, Svilias I, Cepkova J, Mc Grath C \& Maly J. Universal screening detects two-times more thyroid disorders in early pregnancy than targeted high-risk case finding. European Journal of Endocrinology/European Federation of Endocrine Societies 2010163 645-650. (doi:10.1530/EJE-10-0516)

20 Vaidya B, Anthony S, Bilous M, Shields B, Drury J, Hutchison S \& Bilous R. Detection of thyroid dysfunction in early pregnancy: Universal screening or targeted high-risk case finding? Journal of Clinical Endocrinology and Metabolism 200792 203-207. (doi:10.1210/ jc.2006-1748)

21 Ahmed IZ, Eid YM, El Orabi H \& Ibrahim HR. Comparison of universal and targeted screening for thyroid dysfunction in pregnant Egyptian women. European Journal of Endocrinology/European Federation of Endocrine Societies 2014171 285-291. (doi:10.1530/EJE-14-0100)

22 Chang DL, Leung AM, Braverman LE \& Pearce EN. Thyroid testing during pregnancy at an academic Boston Area Medical Center. Journal of Clinical Endocrinology and Metabolism 201196 E1452-E1456. (doi:10.1210/jc.2011-0360)

23 Ohashi M, Furukawa S, Michikata K, Kai K, Sameshima H \& Ikenoue T. Risk-based screening for thyroid dysfunction during pregnancy. Journal of Pregnancy 20132013 619718. (doi:10.1155/2013/619718)

24 Wang W, Teng W, Shan Z, Wang S, Li J, Zhu L, Zhou J, Mao J, Yu X, Li J et al. The prevalence of thyroid disorders during early pregnancy in China: the benefits of universal screening in the first trimester of pregnancy. European Journal of Endocrinology/European Federation of Endocrine Societies 2011164 263-268. (doi:10.1530/EJE-10-0660)

25 Yang H, Shao M, Chen L, Chen Q, Yu L, Cai L, Lin Z, Zhang C \& Lu X. Screening strategies for thyroid disorders in the first and second trimester of pregnancy in China. PLOS ONE 20149 e99611. (doi:10.1371/journal.pone.0099611)

26 Potlukova E, Potluka O, Jiskra J, Limanova Z, Telicka Z, Bartakova J \& Springer D. Is age a risk factor for hypothyroidism in pregnancy? An analysis of 5223 pregnant women. Journal of Clinical Endocrinology and Metabolism 201297 1945-1952. (doi:10.1210/jc.2011-3275)

27 Stagnaro-Green A, Abalovich M, Alexander E, Azizi F, Mestman J, Negro R, Nixon A, Pearce EN, Soldin OP, Sullivan S et al. Guidelines of the American Thyroid Association for the diagnosis and management of thyroid disease during pregnancy and postpartum. Thyroid 201121 1081-1125. (doi:10.1089/thy.2011.0087)

28 Azizi F, Mehran L, Amouzegar A, Delshad H, Tohidi M, Askari S \& Hedayati M. Establishment of the trimester-specific reference range for free thyroxine index. Thyroid 201323 354-359. (doi:10.1089/thy. 2012.0407)

29 Altomare M, La Vignera S, Asero P, Recupero D, Condorelli RA, Scollo P, Gulisano A, Magro E, Tumino D, Tumino S et al. High prevalence of 
thyroid dysfunction in pregnant women. Journal of Endocrinological Investigation 201336 407-411. (doi:10.3275/8658)

30 Gayathri R, Lavanya S \& Raghavan K. Subclinical hypothyroidism and autoimmune thyroiditis in pregnancy - a study in south Indian subjects. Journal of the Association of Physicians of India 200957 691-693.

31 Gesing A, Lewinski A \& Karbownik-Lewinska M. The thyroid gland and the process of aging; what is new? Thyroid Research 2012516. (doi:10.1186/1756-6614-5-16)

32 Kim YA \& Park YJ. Prevalence and risk factors of subclinical thyroid disease. Endocrinology and Metabolism 201429 20-29. (doi:10.3803/ EnM.2014.29.1.20)

33 Vanderpump MP. The epidemiology of thyroid disease. British Medical Bulletin 201199 39-51. (doi:10.1093/bmb/ldr030)

34 Ajmani SN, Aggarwal D, Bhatia P, Sharma M, Sarabhai V \& Paul M. Prevalence of overt and subclinical thyroid dysfunction among pregnant women and its effect on maternal and fetal outcome. Journal of Obstetrics and Gynaecology of India 201464 105-110. (doi:10.1007/s13224-013-0487-y)

35 Benhadi N, Wiersinga WM, Reitsma JB, Vrijkotte TG \& Bonsel GJ. Higher maternal TSH levels in pregnancy are associated with increased risk for miscarriage, fetal or neonatal death. European Journal of Endocrinology/European Federation of Endocrine Societies 2009160 985-991. (doi:10.1530/EJE-08-0953)

36 Negro R, Formoso G, Coppola L, Presicce G, Mangieri T, Pezzarossa A \& Dazzi D. Euthyroid women with autoimmune disease undergoing assisted reproduction technologies: the role of autoimmunity and thyroid function. Journal of Endocrinological Investigation 200730 3-8. (doi:10.1007/BF03347388)

37 Stagnaro-Green A. Thyroid antibodies and miscarriage: where are we at a generation later? Journal of Thyroid Research 20112011841949. (doi:10.4061/2011/841949)
38 Wilson KL, Casey BM, McIntire DD, Halvorson LM \& Cunningham FG. Subclinical thyroid disease and the incidence of hypertension in pregnancy. Obstetrics and Gynecology 2012119 315-320. (doi:10.1097/ AOG.0b013e318240de6a)

39 Abalovich M, Gutierrez S, Alcaraz G, Maccallini G, Garcia A \& Levalle O. Overt and subclinical hypothyroidism complicating pregnancy. Thyroid 200212 63-68. (doi:10.1089/105072502753451986)

40 Velkeniers B, Van Meerhaeghe A, Poppe K, Unuane D, Tournaye H \& Haentjens $P$. Levothyroxine treatment and pregnancy outcome in women with subclinical hypothyroidism undergoing assisted reproduction technologies: systematic review and meta-analysis of RCTs. Human Reproduction Update 201319 251-258. (doi:10.1093/humupd/ dms052)

41 Behrooz HG, Tohidi M, Mehrabi Y, Behrooz EG, Tehranidoost M \& Azizi F. Subclinical hypothyroidism in pregnancy: intellectual development of offspring. Thyroid 201121 1143-1147. (doi:10.1089/ thy.2011.0053)

42 Jayaraman M, Verma A, Harikumar KV, Ugale M \& Modi K. Pregnancy outcomes with thyroxine replacement for subclinical hypothyroidism: Role of thyroid autoimmunity. Indian Journal of Endocrinology and Metabolism 201317 294-297. (doi:10.4103/ 2230-8210.109717)

43 Bulmus N, Ustuner I, Seda Guvendag Guven E, Kir Sahin F, Senturk S \& Baydur Sahin S. Thyroid diseases in pregnancy: the importance of anamnesis. Pakistan Journal of Medical Sciences 201329 1187-1192. (doi:10.12669/pjms.295.3647)

44 Matuszek B, Zakościelna K, Baszak-Radomańska E, Pyzik A \& Nowakowski A. Universal screening as a recommendation for thyroid tests in pregnant women. Annals of Agricultural and Environmental Medicine 201118 375-379.

Received 25 July 2015

Revised version received 28 September 2015

Accepted 28 October 2015 